\title{
Towards a definition of environmental niches in alpine streams by employing chironomid species preferences
}

\author{
Georg H. Niedrist • Leopold Füreder
}

Received: 2 February 2016/Revised: 14 May 2016/Accepted: 17 May 2016/Published online: 28 May 2016

(C) The Author(s) 2016. This article is published with open access at Springerlink.com

\begin{abstract}
Macroinvertebrates are widely used as indicators to detect and assess anthropogenic impacts on freshwater ecosystems. However, despite being considered useful in indicating effects of environmental change in alpine catchments, little is known about species preferences for local conditions in such environments. In exploring the occurrence of 59 taxa within the dipteran family Chironomidae in relation to key-environmental variables in alpine and sub-alpine streams, we showed that sediment load, water temperature, periphyton density, and fine particulate organic matter mostly explain assemblage structures. Two-way-cluster analyses identified stream-type specific assemblages, indicator value analysis defined indicator species for glacial and non-glacial streams, and weighted averaging regression models confined preferences for local environmental conditions by summing their optima and tolerance widths regarding
\end{abstract}

Handling editor: Nuria Bonada

Electronic supplementary material The online version of this article (doi:10.1007/s10750-016-2836-1) contains supplementary material, which is available to authorized users.

G. H. Niedrist $(\bowtie) \cdot$ L. Füreder

River Ecology and Conservation, Institute of Ecology,

University of Innsbruck, Technikerstr. 25,

6020 Innsbruck, Austria

e-mail: g.niedrist@student.uibk.ac.at

L. Füreder

e-mail: leopold.fuereder@uibk.ac.at environmental key factors. The definition of habitat requirements identified stenoecious taxa with preferences for high and low values of respective variables thus identified most suitable indicators for future studies. Our work reveals manifold preferences within the dominant benthic invertebrate family, underlines their enormous potential for monitoring purposes, and is a step forward in better understanding ecosystem properties and biodiversity. Fundamental requirements for these kinds of indicative traits, essential to understand cause-effect relationships in environmental change issues, are a robust taxonomy and a comprehensive set of physical and chemical data.

Keywords Alpine glacier-fed streams · Glacier retreat $\cdot$ Indicator $\cdot$ Autecology $\cdot$ Invertebrates $\cdot$ Subalpine

\section{Introduction}

Organisms, which successfully inhabit extreme environments, are living in the ecological optimum for existence and reproduction (Begon et al., 1996). They tolerate harsh physical environmental conditions, grow at low temperatures, use limited food resources, and cope with predators and competing species (Wharton, 2002). According to the requirement-based concept by Grinnell (1917) and Hutchinson (1957), the term ecological niche was defined as a function 
linking the fitness of individuals to their environment. One species' ecological niche is quantified as a multidimensional hypervolume (Blonder et al., 2014), where the individual dimensions are specific environmental conditions and resources that define the requirements of the present species to persist. Within this consideration, the ecological niche represents the suitable volume that permits positive population growth (Hutchinson, 1957; Hirzel \& Le Lay, 2008). However, the characterisation of such niches in natural multi-species ecosystems is still debated (Soberón, 2007), although independent methods have been developed for different uses (Blonder et al., 2014).

Alpine stream networks are a mosaic of kryal (glacier-melt dominated), rhithral (rain/snowmelt dominated) and krenal (spring-fed, groundwater dominated) rivers (McGregor et al., 1995). Each source of stream generates characteristic conditions regarding physical (water temperature, discharge, substrate dynamics and suspended sediment load) and chemical water quality (Tockner et al., 1997; Füreder et al., 2001; Füreder, 2007), which are also responsible for the variety of environmental conditions further downstream (Brown et al., 2006a). This diverse abiotic character results in wide ecological gradients, suitable for a variety of benthic invertebrate species to coexist in alpine streams (Hutchinson, 1957; Levine \& Hille Ris Lambers, 2009; Blonder et al., 2014). Larvae of the dipteran family Chironomidae typically dominate in streams at high altitude and latitude in terms of abundance and species number (Ward, 1994; Füreder, 1999; Füreder et al., 2001; Lods-Crozet et al., 2001a), and with the increasing harshness, they are often the only insects present (Füreder, 1999; Füreder et al., 2001; Lencioni \& Rossaro, 2005). Considering specific adaptations and unique survival strategies (Danks, 1971; Danks \& Oliver, 1972; Füreder, 1999; Bouchard et al., 2006), some species may be restricted to narrow environmental ranges concerning key environmental parameters (Lencioni \& Rossaro, 2005). Hence, each type of stream (glacial, non-glacial) as well as reaches with low and high inputs of organic material (above and below the treeline) may therefore support a distinct assemblage of chironomid communities (Ward, 1994; Brown et al., 2006b). Many species may live close to their critical limits regarding not only the chemical and physical but also biological environment (Fjellheim et al., 2000). However, preferred ranges, the sensitivity to changes and the constancy of preferences and occurrence are not known for most species.

The benthic biota is expected to possess a high potential to indicate long-term environmental changes not only due to their high abundance in alpine rivers, and adequate species richness, but also because of the observed sensitivity to environmental change (Ward, 1994; Füreder et al., 2001; Milner et al. 2001; Khamis et al., 2014). Several conceptual models (Milner \& Petts, 1994; Milner et al., 2001), distribution and succession concepts (Füreder et al., 2001; Lods-Crozet et al., 2001a) and studies at species level (Lencioni \& Rossaro, 2005) are available for alpine stream ecosystems as well as their key species. Attempting to quantify the effect of accelerated climate alterations (Beniston, 2005) and glacier retreat in alpine regions on benthic invertebrate communities living in glacially influenced streams (Jacobsen et al., 2012) has been a main research aim during the last decade (Brown et al., 2007). However, to date detailed autecological data (e.g., environmental preferences, trophic position, and functional role) are often lacking for invertebrates in alpine stream ecosystems, especially for the ubiquitous dipteran family, the Chironomidae. While most studies have shown relationships between habitat conditions and taxa richness, abundance and diversity, there is a lack of information demonstrating clear, species-specific habitat preferences, as well as niches and their boundaries.

To fill this research gap, we make the first approach to define fine-scale habitat requirements useful for a further niche-definition of chironomid assemblages and key-species in alpine stream habitats. We aim to identify the key environmental drivers that significantly shape the assemblages in order to define the potential species' ecological multidimensional hypervolume. To fulfil this purpose, we used wide gradients in various environmental conditions and in addition, we modelled multiple taxa-specific one-dimensional preferences. Furthermore, we combined them to characterise the multifactorial environmental preferences of the most abundant chironomid species. Based on the classification of the stream-type specific chironomid assemblages, along with the most representative taxa and their consistency of occurrence in the specific stream types in different watersheds, we aimed to identify the most suitable and useful organisms for ecological analysis and monitoring of environmental change. 


\section{Methods}

Study area

The study area was located in the Austrian Central Eastern Alps, within the Hohe Tauern National park in the federal provinces of Salzburg and Carinthia (Fig. 1). In two glaciated catchments, the Anlauf and Seebach Valley (Fig. 1), we collected samples from four different river reaches (two non-glacial, two glacial) in each catchment of 20-30 m length above and below the treeline (Table 1). This sampling strategy was based on previous research conducted in the Hohe Tauern National park (Füreder \& Amprosi, 2001; Füreder et al., 2002). The distance between the studied glacial-stream sites from the same valley were 3.5 and $2.52 \mathrm{~km}$ in Anlauf Valley and Seebach Valley, respectively. We used a paired study design which included replicate sites in the glacial and the spring-fed stream at a certain distance from the glacier in the alpine vegetation zone and further downstream within the montane vegetation zone. Vegetation coverage was scarcer in the Seebach valley at the lower sites, compared with the sites from the Anlauf Valley. Both catchments have the same geographic exposure and are in a natural hydromorphological condition and ecological status.

Sampling procedure

Benthic samples and reach-scale environmental variables were obtained on three occasions within the snow-free season (end of June, beginning of August and mid-September) in 2011. Our goal was to include a wide spectrum of environmental conditions, and as such, the selected streams were of glacial and non-

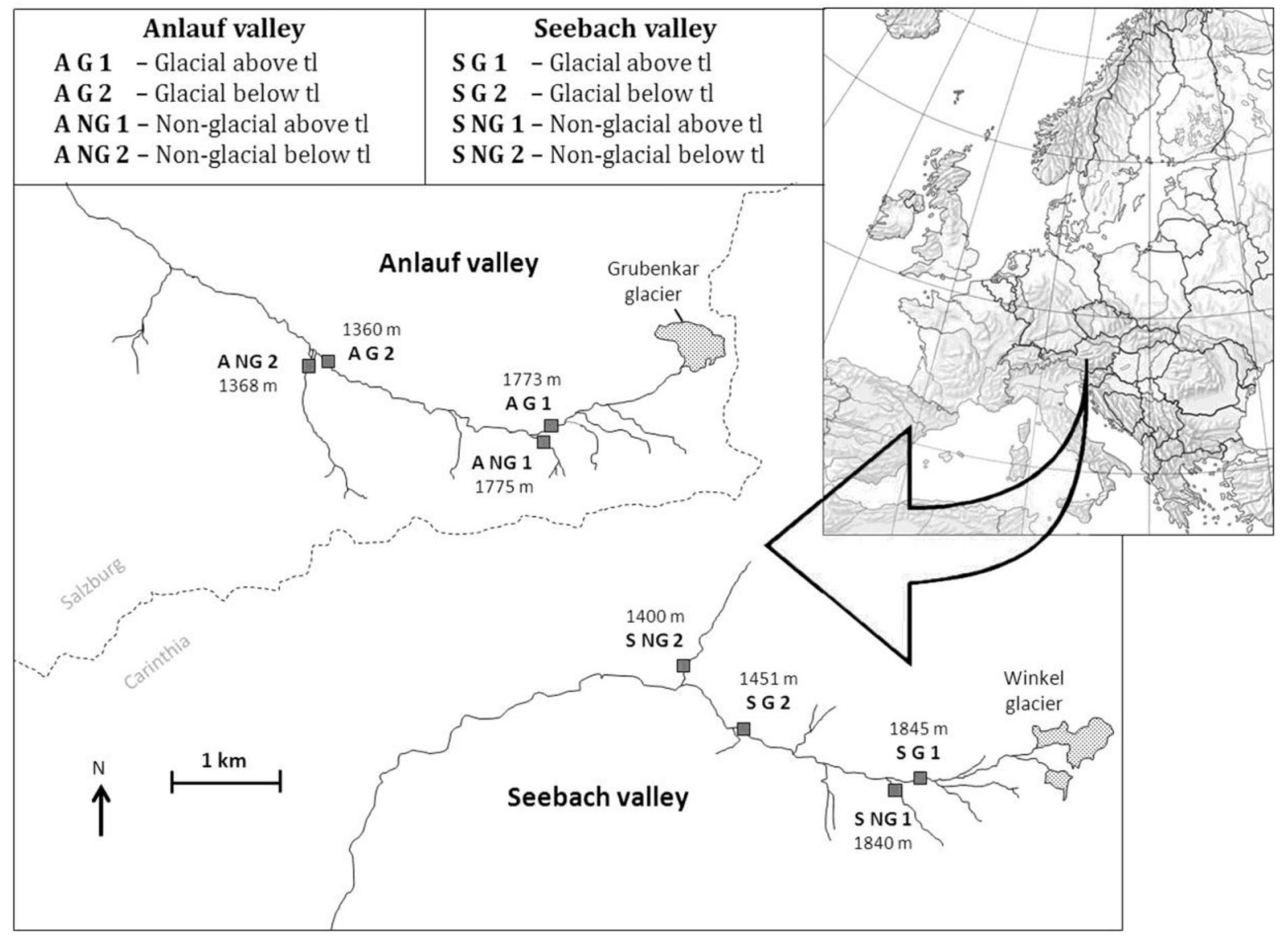

Fig. 1 Study area with the investigated catchments in the Anlauf valley and Seebach valley and the sampling sites in the glacial and non-glacial streams, above and below the treeline ('tl') 
Table 1 Names, abbreviations, altitude and coordinates (WGS 84) of sampling sites in the Anlauf 'A' and Seebach 'S' valleys

\begin{tabular}{lllll}
\hline Valley & Sampling site & Short name & Altitude $(\mathrm{m})$ & Coordinates \\
\hline Anlauf & Glacial above treeline & Glacial above tl-A & 1773 & $47^{\circ} 03^{\prime} 21.3^{\prime \prime} \mathrm{N}, 13^{\circ} 12^{\prime} 26^{\prime \prime} \mathrm{E}$ \\
& Glacial below treeline & Glacial below tl-A & 1360 & $47^{\circ} 03^{\prime} 20.6^{\prime \prime} \mathrm{N}, 13^{\circ} 12^{\prime} 24.7^{\prime \prime} \mathrm{E}$ \\
& Non-glacial above treeline & Non-glacial above tl-A & 1775 & $47^{\circ} 04^{\prime} 00.9^{\prime \prime} \mathrm{N}, 13^{\circ} 09^{\prime} 53.2^{\prime \prime} \mathrm{E}$ \\
& Non-glacial below treeline & Non-glacial below tl-A & 1368 & $47^{\circ} 03^{\prime} 57.5^{\prime \prime} \mathrm{N}, 13^{\circ} 09^{\prime} 55.1^{\prime \prime} \mathrm{E}$ \\
Seebach & Glacial above treeline & Glacial above tl-S & 1845 & $47^{\circ} 00^{\prime} 38.5^{\prime \prime} \mathrm{N}, 13^{\circ} 16^{\prime} 49.9^{\prime \prime} \mathrm{E}$ \\
& Glacial below treeline & Glacial below tl-S & 1451 & $47^{\circ} 01^{\prime} 05.7^{\prime \prime} \mathrm{N}, 13^{\circ} 14^{\prime} 43.8^{\prime \prime} \mathrm{E}$ \\
& Non-glacial above treeline & Non-glacial above tl-S & 1840 & $47^{\circ} 00^{\prime} 35.5^{\prime \prime} \mathrm{N}, 13^{\circ} 16^{\prime} 40.5^{\prime \prime} \mathrm{E}$ \\
& Non-glacial below treeline & Non-glacial below tl-S & 1400 & $47^{\circ} 01^{\prime} 23.2^{\prime \prime} \mathrm{N}, 13^{\circ} 14^{\prime} 10.3^{\prime \prime} \mathrm{E}$ \\
\hline
\end{tabular}

glacial origin and were sampled above and below the treeline.

The study was divided into three major stages: Firstly, we analysed the structure of chironomid communities in different stream types in one valley (Anlauf) including the analysis of seasonal effects to estimate the consistency of the structures. Secondly, we conducted an indicator value analysis, and for the test of suitability and appropriateness, we took samples from one substrate size. This was done based on the highest diversity (Shannon index), evenness and species numbers, and in addition, we compared them with the equivalent samples from the other valley (Seebachtal). Finally, we ordinated all the processed samples from the Anlauf and Seebach valleys together with the environmental data so as to identify the crucial environmental variables significantly related to community patterns. These variables, which demonstrate reach-scale dimensions of chironomids distribution in a multidimensional environment, were used to model the environmental optima and tolerance ranges for the most common chironomid species.

Physical and chemical characterisation

The temperature of the eight river reaches was recorded continuously with digital loggers (Onset TidbiT, MA, U.S.A.) throughout the snow-free season (records at $30 \mathrm{~min}$ intervals). This was summarised as maximum water temperature (highest daily mean) and the temperature variability (deviation of daily mean temperatures). The hydrological and the other physical and chemical parameters were assessed on each sampling date. With regard to the chemical analysis of the stream sites, electrical conductivity, $\mathrm{pH}$ and oxygen concentration were measured with a field multiprobe (WTW MultiLine ${ }^{\circledR} 3430$, Weilheim, Germany). Water samples (2 l) were collected in acidwashed polyethylene bottles and analysed for the following chemical parameters: alkalinity, $\mathrm{Na}^{+}, \mathrm{K}^{+}$, $\mathrm{Ca}^{2+}, \mathrm{Mg}^{2+}, \mathrm{Cl}^{-}, \mathrm{SO}_{4}{ }^{2-}, \mathrm{NH}_{4}{ }^{+}, \mathrm{NO}_{3}{ }^{-}$, dissolved nitrogen $(\mathrm{DN})$, total and dissolved phosphorus $\left(\mathrm{P}_{\text {tot }}\right.$, $\mathrm{P}_{\mathrm{dis}}$ ), and dissolved organic carbon (DOC). Ion chromatography (Dionex 100/500 chromatograph) and Shimadzu TOC 5000 were used for the ionic and DOC analyses, respectively. Suspended inorganic and organic matter $(\mathrm{mg} / \mathrm{l})$ were assessed by filtering the water samples on pre-ashed Whatman GF/Cfilters, dried and ashed in a muffle furnace at $450^{\circ} \mathrm{C}$ for $4 \mathrm{~h}$ according to Heiri et al. (2001). Discharge was measured by depth/velocity transects in each reach using a vane wheel probe (Höntzsch probe ZS25, Waiblingen, Germany). The inorganic sediment load $(\mathrm{mg} / \mathrm{s})$ of each reach per sampling date was modelled as the combination of 'suspended inorganic matter' and 'discharge'.

\section{Biological assessment}

All of the eight reaches were sampled on three occasions within the snow-free season. Within each studied reach and during each survey, six replicate Surber samples (mesh size $100 \mu \mathrm{m}$, area: $30 \times 30 \mathrm{~cm}, 0.09 \mathrm{~m}^{2}$ ) of aquatic invertebrates were collected (72 samples) and preserved in $75 \%$ ethanol. Stratified random sampling was performed, focussing on the three major substrate strata present in the riverbeds, i.e., megalithal (boulders, $>40 \mathrm{~cm}$ grain size, 2 samples), macrolithal (coarse cobbles, 20-40 cm, 2 samples) and mesolithal (cobbles, 
$6.33-20 \mathrm{~cm}, 2$ samples), whereas boulders were sampled on the surface only. For the suitability test, a comparison among the stream-type communities in both watersheds was carried out with a subset of all of the samples. In the laboratory, chironomids were identified to species or species-group level using available and accurate keys (Ferrarese \& Rossaro, 1981; Horn, 1993; Rossaro, 1982). Total abundance was expressed as the number of individuals per $\mathrm{m}^{2}$ for each reach on a given date. Two single samples from different sites were characterised as outliers due to their relative high number of early instar larvae, and therefore, they were not considered in the analyses. Periphyton chlorophyll $a$ concentration was determined from three randomly collected stones in each reach and sampling period after filtering the scraped surface layer suspension onto a Whatman GF/C filter paper. Additionally, we filtered water to assess seston chlorophyll $a$ concentration. Water chlorophyll $a$ concentration was assessed the same way. Concentration was measured using a spectrophotometer (Hitachi U-2000) according to standard methods (Lorenzen, 1967). Contents of benthic coarse and fine particulate organic matter (BCPOM/BFPOM: items bigger/smaller than $1 \mathrm{~mm}$ ) were determined by sieving, drying and ashing the residual sample content at $450^{\circ} \mathrm{C}$ for 4 h (Heiri et al., 2001).

\section{Classification of chironomid assemblages}

For the detection of stream-type specific chironomid community structures in the Anlauf Valley, a cluster analysis (Two-way cluster analysis, PC-ORD 5.01) was performed according to McCune \& Mefford (2006) using samples from all three substrates. For this, the relative mean abundance data of chironomid species from each reach and date was used $(n=6)$. We excluded chironomid species with low abundances within the samples $(<5 \%)$ to avoid unduly large influence of rare species on the analysis (ter Braak \& Smilauer, 1998; Legendre \& Legendre, 1998). A nonparametric permutational multivariate analysis of variance (non-parametric Manova, Anderson, 2005) was conducted to test for differences between the clustered assemblages using PAST software version 2.17c (Hammer et al., 2001). The seasonal effect on community structure was assessed by performing a redundancy analysis (gradient length of 3.0). Chironomid communities, taxa and factor date (June, August and September) were ordinated including Monte Carlo permutation testing (9999 permutations).

In order to test for stream-type specific community structures in all of the stream reaches from both of the valleys, we conducted a second cluster analysis (Twoway cluster analysis) from Anlauf and Seebach Valley stream reaches ( $n=6$, grouped dates). We grouped these samples according to their faunal composition using Sфrensen's similarity coefficient and group average linkage. For this, we used the relative mean abundance data of the chironomid taxa in the samples of each stream reach. The data were square rooted to reduce the analytical influence of dominant species (Kindt \& Coe, 2005). Due to marginal seasonal differences in the Anlauf Valley assemblage structures (factor date accounted for only $8.6 \%$ of the total variation), samples from different months were grouped for each stream type in both valleys ('Glacial above treeline') in Anlauf ('A') and Seebach ('S') Valley, respectively ('Glacial above tl S'). To reveal the chironomid species that best characterised the group of sites, we conducted an indicator value analysis (IndVal; Dufrêne \& Legendre, 1997) for grouped stream types showing similar community structures in both valleys. This method combines the abundance and the faithfulness of occurrence of a chironomid species in a particular stream reach (McCune et al., 2002). Indicator values emphasise the importance of different habitats for different species and identify the indicator species for each habitat, for example, a high and significant indicator value (\%) of a species in a certain stream reach indicates its high frequency and abundance restricted to that habitat. Indicator values were calculated for each species and a Monte Carlo method was used to test the statistical significance (9999 permutations) using PC-ORD version 5 (McCune \& Mefford, 2006).

\section{Identification of environmental parameters crucial for chironomid community structures}

The detection of analog community structures in both valleys (see Fig. 3) involved the inclusion of all the available samples from the Anlauf and Seebach Valleys for the identification of significant explanatory environmental variables. Chironomid communities, taxa and significant parameters were ordinated using a redundancy analysis, although we excluded chironomid species with low abundances within the 
samples $(<5 \%)$ and those two single samples with a high density of bryophytes to avoid a high proportions of juvenile larvae and thus low taxonomic resolution (two samples). Both, biotic and abiotic data were transformed to reduce skewed distributions (tested with Kolmogorov-Smirnov test, $P<0.05$ ): environmental data shown in percentage (BFPOM, BCPOM) were square-root transformed (Legendre \& Legendre, 1998; Li et al., 2012); the remaining environmental variables, with the exception of $\mathrm{pH}$, and chironomid abundances were $(\ln (x+1))$ transformed $(\mathrm{Li}$ et al., 2012). The automatically calculated gradient length of $<3$ standard deviations implied the use of a linear model such as a redundancy analysis (RDA) best fitting the data (Lepš \& Šmilauer, 2003). Significant variables explaining the distribution of chironomid species in the sampled reaches were chosen by the forward selection method (Blanchet et al., 2008), and the significance of the RDA axes was determined by Monte Carlo permutation testing (9999 permutations) of the eigenvalues using CANOCO 5.0 software (Šmilauer \& ter Braak, 2012). In this case, all of the biotic and abiotic environmental parameters (24) were included (see Annex 1-Supplemmentary Material).

\section{Weighted averaging regression modelling}

To quantify the relationships between the environmental variables showing the highest loads in the RDA (conductivity, fine particulate organic matter content (FPOM), maximum water temperature, temperature variability, chlorophyll $a$ concentration, inorganic sediment load and periphyton chlorophyll $a$ concentration) and the most abundant chironomid taxa, weighted averaging regression models (WARMs) were built using c2 version 1.7.4. (Juggins, 2007). The optimal values of the taxa were calculated as the mean of the selected environmental variables weighted by the abundance of the taxa at all sites according to ter Braak \& Juggins (1993):

Weighted average $=\frac{\sum_{i-1}^{n} x_{i} \times y_{i j}}{\sum_{i-1}^{n} y_{i j}}$.

The weighted average shows the estimated species optimum, $x_{i}$ is the environmental variable at site $i$, and $y_{i j}$ stands for the abundance of species $j$ in sample $i$. Additionally, tolerance values were calculated as the weighted standard deviation of the species abundance in all of the samples according to ter Braak \& Juggins (1993):

Tolerance $=\sqrt{\frac{\sum_{i-1}^{n}\left(x_{i}-\text { weighted average }\right)^{2} \times y_{i j}}{\sum_{i-1}^{n} y_{i j}}}$.

For the evaluation of the models' precision, the coefficients of determination $\left(R^{2}\right)$ for the relationships between observed and generated environmental variables were compared. Errors were estimated using bootstrapping ( 9999 bootstrap cycles) integrated in the software C2 (Juggins, 2007). We performed the weighted averaging regression models using untransformed abundance and environmental data. Ecologically not worthwhile subzero tolerance ranges were truncated.

\section{Results}

Chironomid assemblage structure

More than 37,000 chironomids were sorted and identified from 84 samples. Chironomids (Diptera: Chironomidae) were the dominant insect family with 22,179 specimens and 59 taxa in the Anlauf valley (Annex 2-Supplemmentary Material), accounting for more than $60 \%$ of all collected individuals. Other major groups in these reaches were Ephemeroptera, Plecoptera and other dipteran families such as Simuliidae. The mean chironomid abundance ranged from 291 (Glacial above tl-Anlauf in September) to 7456 individuals per $\mathrm{m}^{2}$ (non-glacial above tl-Anlauf in June). Generally, the mean abundance of the chironomidae, but also of all the other macroinvertebrates, was much lower in both glacier-fed (812 and 464 individuals $\mathrm{m}^{-2}$ ) than in the non-glacial reaches $(6170$ and 4527 individuals $\mathrm{m}^{-2}$ ). Both glacier-fed reaches had significantly less chironomids than the two nonglacial rivers (Kruskal-Wallis test, pooled samples with $n=18, P<0.001)$. There were clear spatial distinctions in the chironomid densities according to the different river types; however, only marginal and non-significant seasonal differences were found with the highest densities in June for all the reaches. The subfamily Diamesinae dominated in reaches above the treeline $(84.4 \%$ of all the chironomids in the glacial and $50.4 \%$ in the non-glacial reaches). On the other hand, the subfamily Orthocladiinae showed higher 
relative abundances in reaches below the treeline (77.6\% in the glacial and $98.4 \%$ in the non-glacial reaches). Generally, Orthocladiinae showed significantly higher abundances in the non-glacial streams when compared with the glacial streams $(P<0.001$ for above and below the treeline).

Among the sampled substrates, mesolithal $(6.33-20 \mathrm{~cm})$ samples had the highest chironomid diversity in each stream type in the Anlauf Valley ranging from 3.1 (above the treeline) to 3.9 (below the treeline) in the glacial stream (Table 2). Additionally, in all of the reaches, we found the highest species number in mesolithal samples. The seasonal effect was small, explaining only $8.6 \%$ of the total variation.

River-type specific chironomid assemblages and indicator species

The chironomid communities in all of the stream reaches from the Anlauf valley sampled on the three different occasions clustered in four groups (Fig. 2): the PERMANOVA test found significant differences in the chironomid composition between these groups ( $F: 18.61 ; P<0.05)$. While communities in the different glacial reaches were moderately dissimilar, those communities in the non-glacial streams at different altitudes hosted very different chironomid communities. Furthermore, well-separated communities were established in distinct stream types, but at the same altitudes. Communities from the same habitat differed only slightly seasonally and grouped together in significantly different groups (Fig. 2). The combination of Shannon-index, evenness and taxa number demonstrated that mesolithal substrate inhabits the most diverse, taxa rich and uniformly distributed chironomid communities in the studied streams

Table 2 Shannon diversity, (shannon-) evenness and taxa number of chironomid communities of the studied substrates (megalithal: $>40 \mathrm{~cm}$ diameter; macrolithal: $20-40 \mathrm{~cm}$
(Table 2). Thus, we chose samples from this substrate to compare community structures in both valleys. Communities in comparable stream types above the treeline in both catchments (glacial and non-glacial headwater sites) clustered in the same groups, whereas habitats below the treeline did not show any general community structures (Fig. 3).

The grouping of taxa revealed groups of chironomid taxa with main occurrences in one, two, or three stream reaches (Fig. 3). Taxa mainly occurring in alpine/subalpine glacier-fed -streams were Diamesa steinboecki (Goetghebuer), Diamesa latitarsis-gr. I and II, Diamesa sp. Other taxa that uniformly appeared mainly in high non-glacial streams were Pseudokiefferiella parva (Edwards), Diamesa cinerella/zernyi-gr. and Paratrichocladius rufiventris (Meigen). The third cluster was characterised by various taxa occurring either in one, two or three different habitats. Moreover, in this cluster no uniform distributions were found in the same habitats from the different valleys.

The IndVal procedure revealed chironomid taxa that significantly characterised each of the clustered sites (Table 3). The group of alpine/subalpine stream habitats with glacial influence was best characterised by the taxa $D$. steinboecki and the D. latitarsis-gr. I, whereas indicative species for non-glacial stream habitats above the treeline were $P$. parva, $D$. cinerella/zernyi-gr. and Orthocladius frigidus (Zetterstedt). No general faunal patterns were found for the lower elevation stream habitat types; different chironomid taxa represented these habitats: Tvetenia bavarica (Goetghebuer), Eukiefferiella brevicalcar (Kieffer) and Eukiefferiella fuldensis (Lehmann) were found to be indicator species for low-altitude reaches (Table 3).

diameter; mesolithal: $6.33-20 \mathrm{~cm}$ diameter) in each of the 4 stream reaches in the Anlauf valley

\begin{tabular}{|c|c|c|c|c|c|c|c|c|c|c|c|c|}
\hline \multirow{3}{*}{$\begin{array}{l}\text { Stream origin } \\
\text { Location } \\
\text { Sampled substrate } \\
\text { (-lithal) }\end{array}$} & \multicolumn{6}{|c|}{ Glacial stream } & \multicolumn{6}{|c|}{ Non-glacial streams } \\
\hline & \multicolumn{3}{|c|}{ Above tl } & \multicolumn{3}{|c|}{ Below tl } & \multicolumn{3}{|c|}{ Above tl } & \multicolumn{3}{|c|}{ Below tl } \\
\hline & Macro- & Mega- & Meso- & Macro- & Mega- & Meso- & Macro- & Mega- & Meso- & Macro- & Mega- & Meso- \\
\hline Shannon Index & 3.0 & 2.4 & 3.1 & 3.8 & 2.9 & 3.9 & 3.0 & 3.3 & 3.3 & 2.7 & 2.4 & 3.4 \\
\hline Eveness & 0.7 & 0.6 & 0.7 & 0.9 & 0.6 & 0.8 & 0.7 & 0.7 & 0.7 & 0.6 & 0.5 & 0.7 \\
\hline Number of taxa & 22 & 20 & 22 & 20 & 29 & 28 & 24 & 27 & 27 & 23 & 26 & 31 \\
\hline
\end{tabular}

'tl' stands for treeline, the highest values are shown in bold 


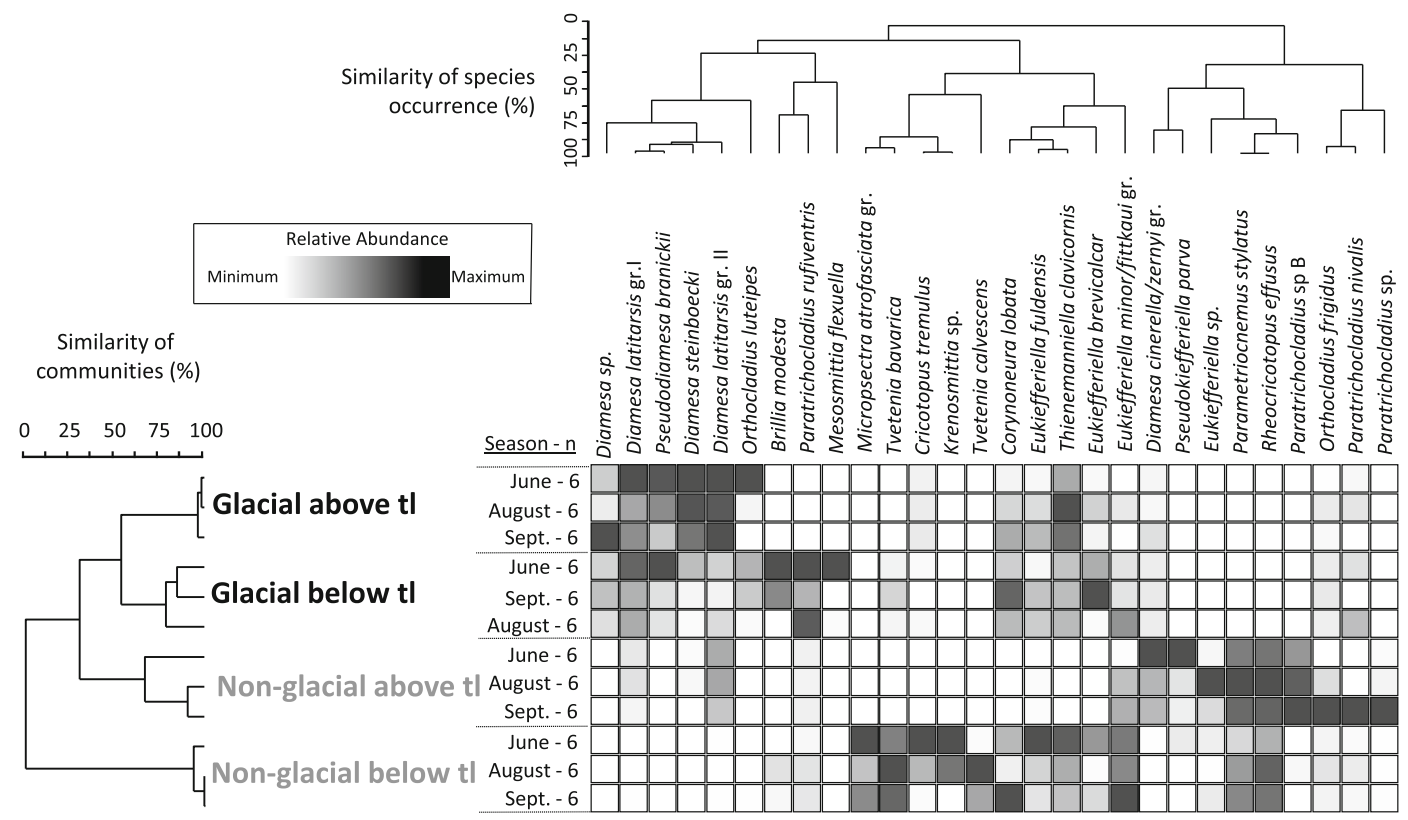

Fig. 2 Two-way cluster of (I) the most abundant chironomid taxa (top) and (II) stream-reach community structures (left) in glacial and non-glacial stream habitats above ('above $\mathrm{tl}^{\text {') }}$ and below ('below tl') the treeline in the Anlauf Valley. Habitats were clustered according to their mean relative abundance of chironomid taxa, and taxa were clustered according to their relative mean abundance in different habitats $(n=6)$. The data matrix expresses the relative mean abundance of species in different habitats

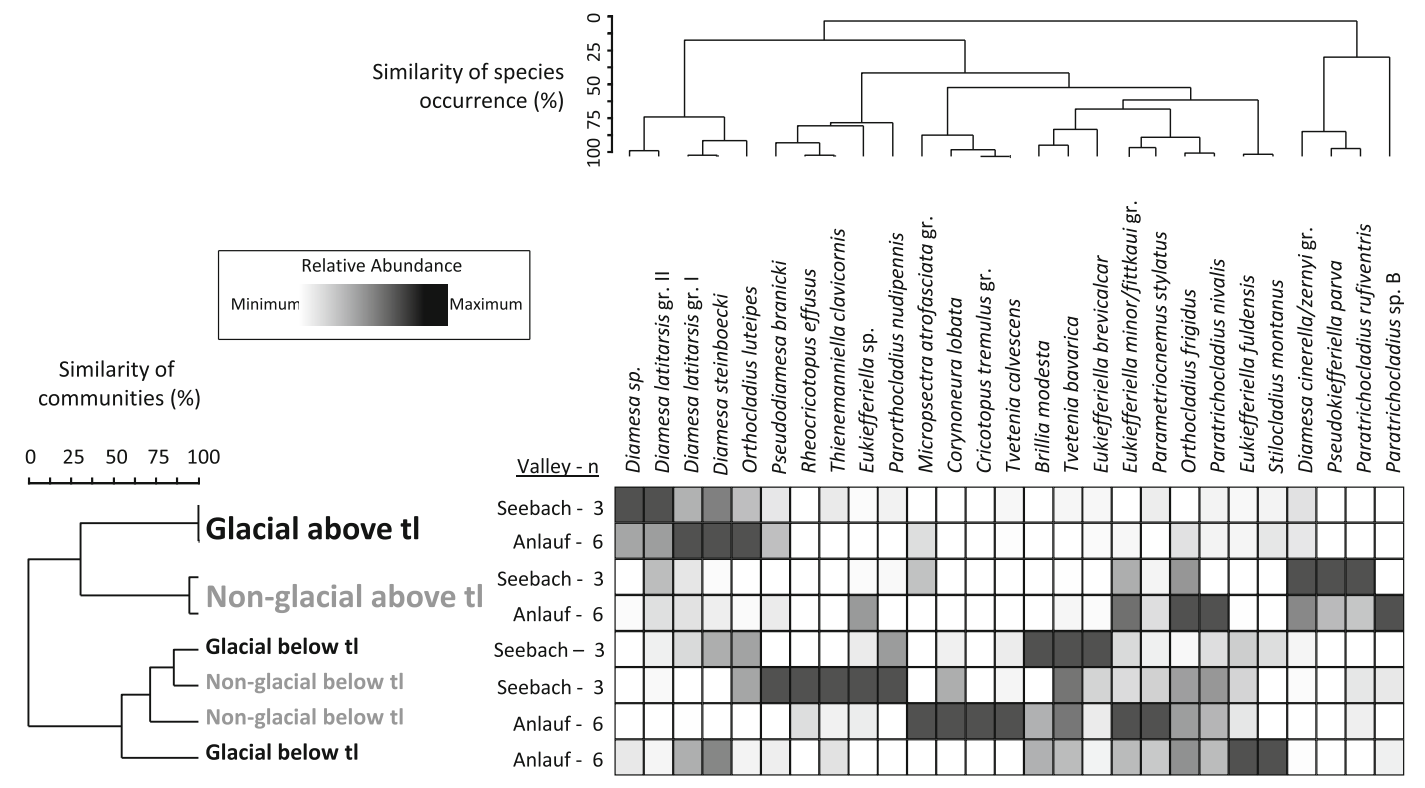

Fig. 3 Two-way cluster of (I) the most abundant chironomid taxa (top) and (II) the mean stream-reach community structures (left): In the Anlauf Valley ("Anlauf") and Seebach Valley ("Seebach"), the glacial and non-glacial stream habitats from the substrate mesolithal above ("above tl") and below ("below tl") the treeline were clustered according to their grouped mean relative abundance of chironomid taxa throughout the snow-free season (n Anlauf Valley $=6 ; n$ Seebach Valley $=3$ ) 
Table 3 Indicator values (IndVal, in percentage of perfect indication) of significant chironomid taxa $(P<0.05 ; 9,999$ permutations) for significantly grouped assemblages identified by cluster analysis including habitats of both catchments (Fig. 3)

\begin{tabular}{llllc}
\hline Stream type & Groups of habitats & Chironomid taxa & Indicator value $(\%)$ & $P$ value \\
\hline Glacial streams_above & Glacial above tl Anlauf & Diamesa steinboecki & 69.7 & 0.033 \\
& Glacial above tl Seebach & Diamesa latitarsis-gr. I & 66.7 & 0.046 \\
Non-glacial streams_above & Non-Glacial above tl Anlauf & Pseudokiefferiella parva & 100 & 0.038 \\
& Non-glacial above tl Seebach & Diamesa cinerella/zernyi-gr. & 79.3 & 0.043 \\
& & Orthocladius frigidus & 52.9 & 88.3 \\
Glacial streams_below & Glacial below tl Anlauf & Tvetenia bavarica & 80 & 0.035 \\
& Glacial below tl Seebach & Eukiefferiella brevicalcar & 80 & 0.046 \\
Non-glacial streams_below & Non-glacial below tl Anlauf & Eukiefferiella fuldensis & 8.012 \\
& Non-glacial below tl Seebach & & &
\end{tabular}

'Above' and 'Below' denote the sampling sites above and below the treeline ('tl'), whereas 'glacial' and 'non-glacial' stand for glacial and non-glacial streams in both valleys Anlauf and Seebach valley

Relationship between chironomid communities and environmental variables

The redundancy analysis including all of the samples revealed a correlation among the samples, the selected local environmental characteristics, along with the distribution patterns of chironomid taxa (Fig. 4). All significant explanatory variables accounted for $48.6 \%$ of the total variation. The first axis, explaining $27.54 \%$ of the total variance ( $F$-ratio: $27.0 ; P<0.001$ ), was positively related to FPOM and water chlorophyll $a$ content and negatively with conductivity. The second axis explained $10.63 \%$ of the total variance ( $F$-ratio: $6.7 ; P<0.001$ ). This axis was positively related with periphyton chlorophyll $a$ concentration, and negatively with temperature variability, maximum
Fig. 4 RDA of samples and chironomid taxa (dots) significantly explaining environmental features and chemical variables (arrows) in surveyed river reaches. Single samples are displayed with circles (glacier-fed reaches) and squares (non-glacial reaches) with reaches above (empty) and below (filled) the treeline. For taxa codes, see Annex 2-

Supplemmentary Material

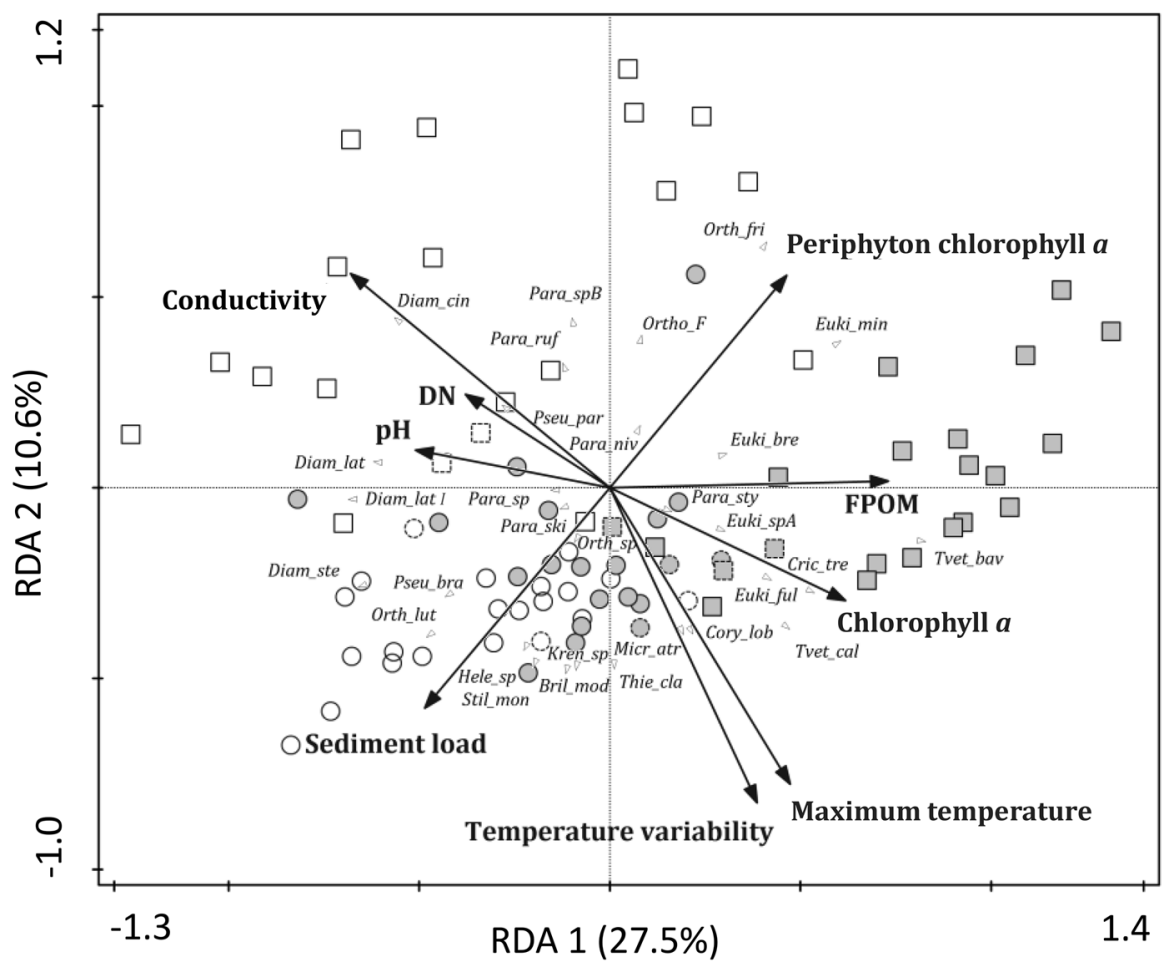


Table 4 Predictive power of weighted averaging regression models (WARM's) for environmental variables in alpine streams: coefficient of determination $\left(R^{2}\right)$ and root-meansquare-error (RMSE) with and without bootstrapping (9999 cycles)

\begin{tabular}{lllrc}
\hline Variable & $R^{2}$ & $R^{2}$ boot & RMSE & RMSE $_{\text {boot }}$ \\
\hline Conductivity & 0.52 & 0.47 & 32.08 & 32.74 \\
FPOM & 0.54 & 0.48 & 3.91 & 3.99 \\
Max. temperature & 0.41 & 0.36 & 2.66 & 2.68 \\
Temperature variability & 0.44 & 0.39 & 2.43 & 2.42 \\
Water Chl $a$ conc. & 0.37 & 0.33 & 0.21 & 0.21 \\
Inorganic sediment load & 0.30 & 0.23 & 23.49 & 23.17 \\
Periphyton chl $a$ conc. & 0.30 & 0.22 & 8.28 & 7.83 \\
\hline
\end{tabular}

Remarkable differences imply low accuracy of the model

Water Chl $a$ conc. stands for the chlorophyll a concentration in the running water

water temperature, and to a lesser extent with inorganic sediment load. The third axis, accounting for only $3.7 \%$ of the total variance, correlated positively with the dissolved nitrogen and negatively with the total phosphorus concentration. The chironomid communities had different structures of taxa when comparing sampling sites above and below the treeline, as well as glacial and non-glacial stream reaches of the same altitude. Most species of the subfamily Diamesinae (except $D$. cinerella/zernyigr.) prevailed in the higher altitude, cold and temperature-stable stream reaches with high inorganic sediment loads and low concentrations of organic matter. Other species (mainly members of Orthocladiinae and some Chironominae) dominated in reaches with higher and more dynamic temperature regimes as well as high primary production enriched with particulate organic material. The variable 'alkalinity' was correlated with 'conductivity' and was therefore excluded prior to the analysis.

Weighted averaging regression models

Conductivity, fine particulate organic matter content (FPOM), maximum water temperature, temperature variability, chlorophyll a concentration, inorganic sediment load, and periphyton chlorophyll $a$ concentration were selected to evaluate the optimal requirements for selected chironomid taxa. These variables provided the highest explanatory power in the RDA.
Fig. 5 Modelled optima and tolerances of key-environmental variables for related chironomid species obtained by weighted averaging regression modelling with indication of species frequency in percentage of all of the samples: a maximum water temperature, b temperature variability, c inorganic sediment load, d conductivity, e chlorophyll a concentration 'Chl a concentration', f FPOM. Dots indicate optimal values, standard deviations show the tolerance ranges. Inferred sub-zero values were truncated

Most regression coefficients $\left(R^{2}\right)$ between the observed and inferred environmental variables were high and similar with and without the bootstrapping tests (Table 4); thus, the best environmental variables influencing the chironomid taxa were modelled reliably by the weighted averaging regression models. The selected taxa differed considerably in their environmental preferences. Whilst we detected a substantial number of generalists, we identified several specialists showing narrow preference ranges for the most important environmental variables. Here we focused on the most frequent taxa in all of the samples (Fig. 5): T. bavarica and E. fuldensis showed preferences for streams with low conductivity (10-50 $\mu \mathrm{S} /$ $\mathrm{cm}$ ), whereas D. latitarsis-gr. I and II, D. cinerella/ zernyi-gr., as well as $O$. frigidus occurred predominantly in streams with higher ionic contents (40-170 $\mu \mathrm{S} / \mathrm{cm})$. Taxa preferring low benthic FPOM content (0-4\% of samples dry weight) were D. steinboecki, D. latitarsis-gr. I and II, and D. cinerella/zernyi-gr., and those living in streams with higher concentrations (until 16\%) were T. bavarica, E. fuldensis, Tvetenia calvescens (Edwards) and E. minor/fittkaui-gr. The best and most frequent indicators for low maximum water temperatures $\left(3.5-9^{\circ} \mathrm{C}\right)$ and low temperature variability $\left(0-5^{\circ} \mathrm{C}\right)$ were $D$. cinerella/zernyi-gr., $D$. latitarsis-gr. I and II, whereas taxa related to high maximum water temperatures $\left(8.5-12.5^{\circ} \mathrm{C}\right)$ and variability $\left(5-9^{\circ} \mathrm{C}\right)$ were E. fuldensis and T. bavarica. With regard to inorganic sediment loads, most taxa showed optimal values around zero; however, $D$. latitarsis-gr. I, Orthocladius luteipes (Goetghebuer) and D. steinboecki showed their optima with 10,18 and $23 \mathrm{~g} / \mathrm{s}$, respectively. The chironomid taxa did not show narrow tolerances for periphyton chlorophyll $a$ content. Nevertheless, D. steinboecki and O. luteipes had preferences for lower concentrations $(0-11 \mu \mathrm{g} /$ $\mathrm{cm}^{2}$ ), whereas the optimal periphyton density for frequent taxa like E. fuldensis, E. brevicalcar and $O$. 
(a)

maximum water temperature $\left[{ }^{\circ} \mathrm{C}\right]$

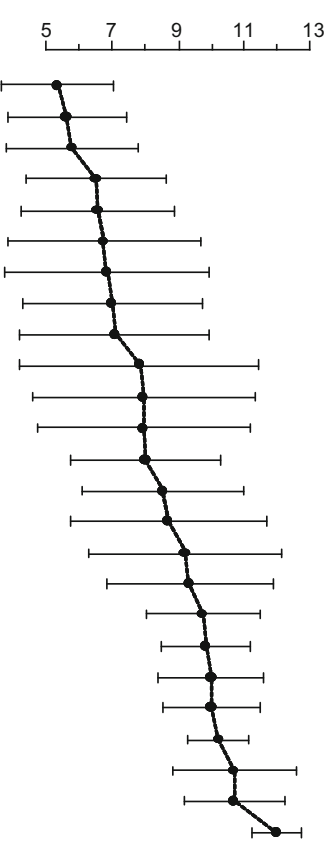

Frequency ( $\%$ of all samples ) of chironomid taxa

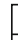

- Paratrichocladius sp. B

- Diamesa cinerella / zernyi gr.

- Pseudokiefferiella parva

- Diamesa latitarsis gr. II

- Diamesa latitarsis gr. I

- Orthocladius frigidus

- Paratrichocladiusnivalis

Orthocladiinae spp.

- Paratrichocladius rufiventris

- Pseudodiamesa branicki

- Parametriocnemus stylatus

Orthocladius sp.

Diamesa steinboecki

- Orthocladius luteipes

Eukiefferiella brevicalcar

- Eukiefferiella fittkaui/minor gr.

Eukiefferiella sp. A

Eukiefferiella fuldensis

Cricotopus Tremulus gr. I

- Micropsectra atrofasciata gr.

Thienemanniella clavicornis

Stilocladius montanus

Tvetenia bavarica

Corynoneura lobata

Tvetenia calvescens

(b)

\section{temperature variability $\left[{ }^{\circ} \mathrm{C}\right]$}
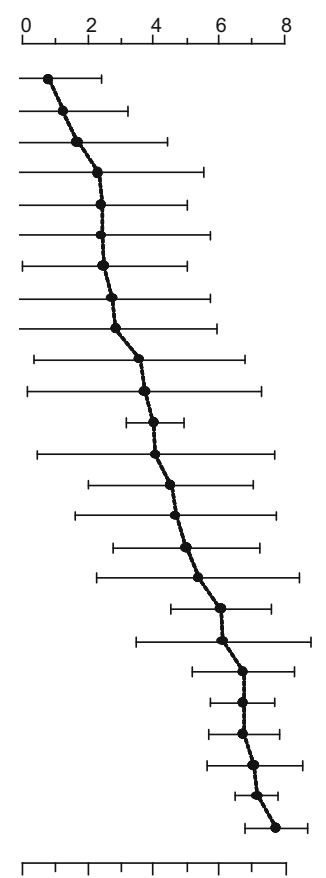

(c)

Inorganic sediment load [g/s]
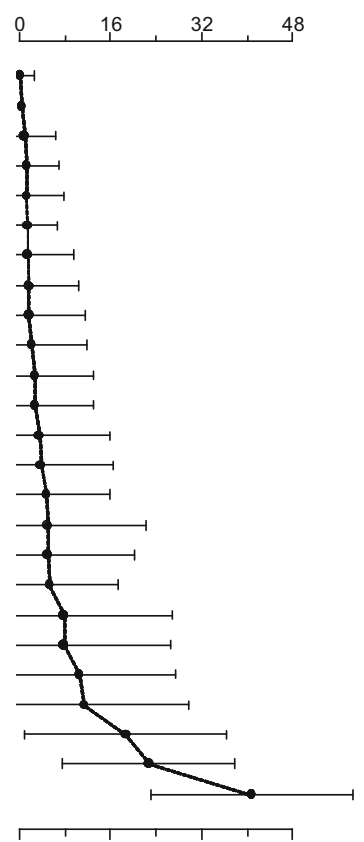

Frequency ( $\%$ of all samples ) of chironomid taxa

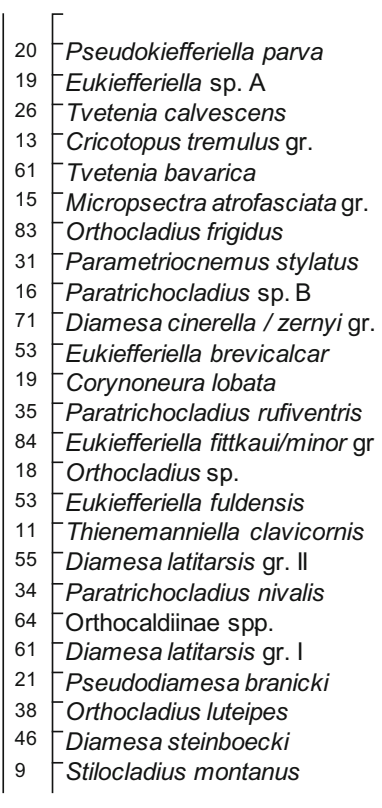

Conductivity $[\mu \mathrm{S} / \mathrm{cm}]$
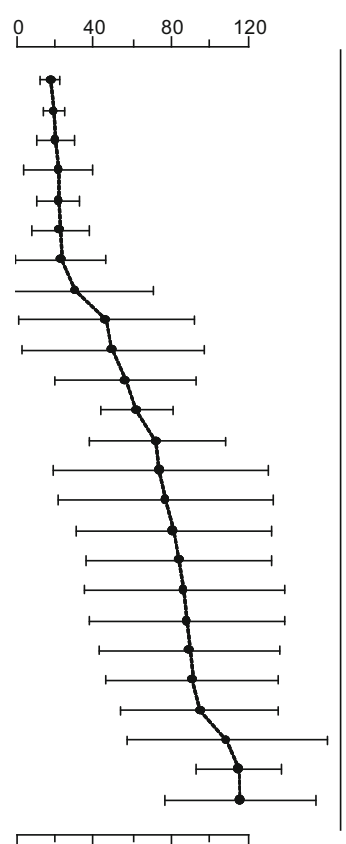

Frequency ( $\%$ of all samples ) of chironomid taxa

\begin{tabular}{|l}
\hline \\
\hline
\end{tabular}

- Paratrichocladius sp. B

- Diamesa cinerella / zernyi gr.

Pseudokiefferiella parva

- Paratrichocladius nivalis

- Diamesa latitarsis gr. I

Orthocladius frigidus

- Diamesa latitarsis gr. II

- Orthocladiinae spp.

- Paratrichocladius rufiventris

- Pseudodiamesa branicki

- Parametriocnemus stylatus

Stilocladius montanus

Orthocladius sp.

- Diamesa steinboecki

Eukiefferiella brevicalcar

- Orthocladius luteipes

Eukiefferiella fittkaui/minor gr.

- Thienemanniella clavicornis

- Eukiefferiella sp. A

Eukiefferiella fuldensis

- Corynoneura lobata

Micropsectra atrofasciata gr.

- Tvetenia bavarica

Cricotopus tremulus gr.

- Tvetenia calvescens (d)

Frequency ( $\%$ of all samples ) of chironomid taxa

-Cricotopus tremulus gr.

Tvetenia calvescens

- Micropsectra atrofasciata gr.

Tvetenia bavarica

- Corynoneura lobata

- Thienemanniella clavicornis

Eukiefferiella fuldensis

-Eukiefferiella sp. A

Eukiefferiella fittkaui/minor gr.

- Eukiefferiella brevicalcar

- Orthocladius luteipes

Stilocladius montanus

- Diamesa steinboecki

- Parametriocnemus stylatus

- Orthocladius sp.

Pseudodiamesa branicki

-Orthocladiinae spp.

Paratrichocladius rufiventris

- Diamesa latitarsis gr. II

Orthocladius frigidus

- Paratrichocladius nivalis

Diamesa latitarsis gr. I

- Pseudokiefferiella parva

Paratrichocladius sp. B

-Diamesa cinerella / zernyi gr. 
chlorophyll a concentration $[\mu \mathrm{g} / \mathrm{l}]$

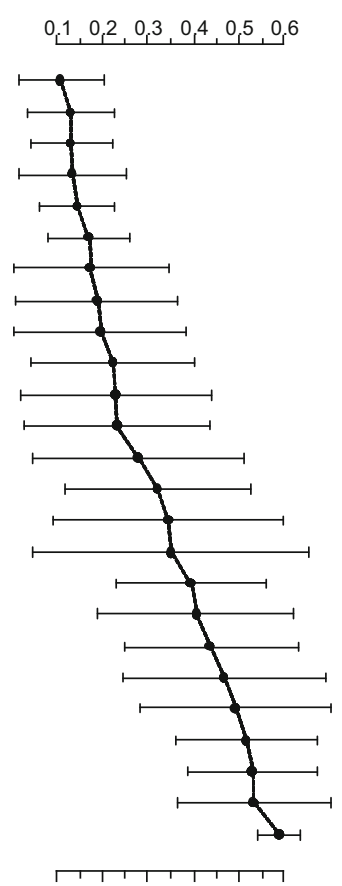

(e)

Frequency ( $\%$ of all samples ) of chironomid taxa

55 - Diamesa latitarsis gr. II

16 - Paratrichocladius sp. B

61 - Diamesa latitarsis gr. I

21 - Pseudodiamesa branicki

71 - Diamesa cinerella / zernyi gr.

- Diamesa steinboecki

- Orthocladius luteipes

- Pseudokiefferiella parva

5 - Paratrichocladius rufiventris

34 - Paratrichocladius nivalis

64 -Orthocladiinae spp.

83 - Orthocladius frigidus

31 - Parametriocnemus stylatus

8 -Orthocladius sp.

3 -Eukiefferiella brevicalcar

1 - Thienemanniella clavicornis

Stilocladius montanus

84 Eukiefferiella fittkaui/minor gr.

19 - Corynoneura lobata

15 - Micropsectra atrofasciata gr.

19 -Eukiefferiella sp. A

61 Tvetenia bavarica

26 - Tvetenia calvescens

53 - Eukiefferiella fuldensis

13 -Cricotopus tremulus gr.

Fig. 5 continued

frigidus varied between 15 and $16.5 \mu \mathrm{g} / \mathrm{cm}^{2}$. Chlorophyll $a$ concentrations in the running water were generally low. D. latitarsis-gr. II and I, D. cinerella/ zernyi-gr. and D. steinboecki are taxa tolerating concentrations until $0.25 \mu \mathrm{g} / \mathrm{l}$, and on the other hand we found T. bavarica, T. calvescens and E. fuldensis living in productive streams with concentrations between 0.35 and $0.65 \mu \mathrm{g} / \mathrm{l}$.

\section{Discussion}

Biodiversity in alpine areas is threatened by ever increasing land use and the effects of other human activities including rapid climate change. Even in relatively remote regions, e.g., high mountain protected areas, alpine stream ecosystems experience the consequences of climatic change including glacier retreat, altered water temperature, discharge dynamics as well as the availability of allochthonous and autochthonous organic matter (Braun et al., 2000; Zah \& Uehlinger, 2001; Jansson et al., 2003; Knowles et al., 2006; Zemp et al., 2006). Research to determine (f)
FPOM [\% of dry weight]
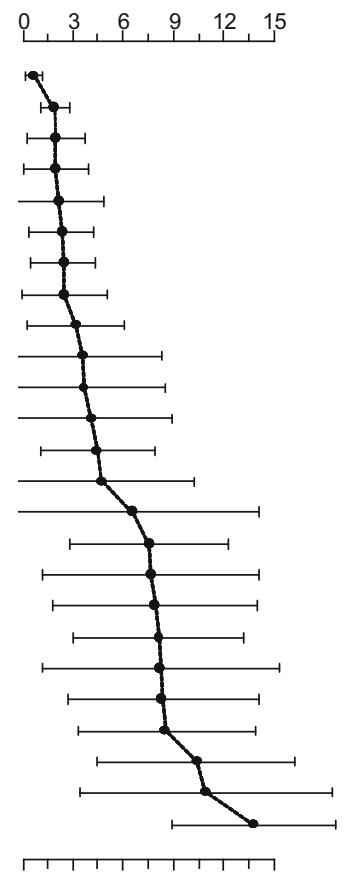

Frequency ( $\%$ of all samples ) of chironomid taxa

Stilocladius montanus

- Diamesa steinboecki

Diamesa latitarsis gr. I

- Diamesa latitarsis gr. II

- Paratrichocladius sp. B

- Diamesa cinerella / zernyi gr.

- Pseudokiefferiella parva

- Pseudodiamesa branicki

- Paratrichocladius rufiventris

Orthocladius luteipes

Orthocladius frigidus

Parametriocnemus stylatus

Orthocladiinae spp.

Orthocladius sp.

Corynoneura lobata

Thienemanniella clavicornis

Eukiefferiella fittkaui/minor gr.

Tvetenia calvescens

Eukiefferiella brevicalcar

Eukiefferiella fuldensis

Eukiefferiella sp. A

- Tvetenia bavarica

Micropsectra atrofasciata gr.

- Cricotopus tremulus gr.
- Paratrichocladius nivalis

the causal relationships between environmental characteristics and the distribution of aquatic organisms has resulted in several predictions of climate change effects on these unique ecosystems (Muhlfeld et al., 2011; Giersch et al., 2015). In this respect, understanding the spatial and temporal patterns, as well as the determinants of the structure of chironomid assemblages, which form the main components of the benthic invertebrate fauna (Füreder et al., 2001; Lods-Crozet et al., 2001a), are fundamental for the application of this ubiquitous dipteran family as indicators (Butler et al., 2012). For this purpose, we found it essential to define species-specific environmental requirements, to provide new insights into the range of species occurrence and their preferences.

This study has significantly enhanced the understanding of the relationship of reach-scale environmental conditions and macroinvertebrate assemblages across various alpine and sub-alpine stream types. It contributes, based on high-resolution data, novel definitions of environmental preferences of chironomid species, which explain the consistent stream-type specific occurrence of species and species-groups in 
two watersheds in the Central European Alps. Along these lines, we undertook a redundancy analysis of chironomid species assemblages from different stream types in combination with a comprehensive set of finescale environmental parameters. We identified key environmental variables significantly influencing chironomid community structures and found that taxaspecific differences in modelled preferences for these environmental variables provoke the formation of stream-type specific chironomid assemblages in headwater streams with and without glacial influence. Taking into account all of the aforementioned, we are able to discuss the following:

Multifactorial effect of environmental stressors

on chironomid assemblages

and the characterisation of niche space

of chironomidae in alpine and sub-alpine streams

The influence of environmental factors on alpine stream invertebrate communities was mainly studied in glacier-fed streams (e.g. Brittain \& Milner, 2001; Milner et al., 2001). These studies identified maximum water temperature, Pfankuch-index and distance from the source as the main influences on community structures. Our results from all of the investigated stream types in both catchments indicated that additional environmental parameters contributed significantly to the structuring of chironomid communities. There is evidence that not only water temperature but also periphyton chlorophyll a content, and fine particulate organic material played an important role in shaping alpine stream invertebrate assemblages, as initially supposed by Milner et al. (2001). The availability of broad food sources (FPOM, algae) had a major effect on chironomid community structures, reinforcing the assumptions of Clitherow et al. (2013) that diatoms, periphyton and fine detritus form dominant food sources for invertebrates, especially in groundwater fed alpine streams (Zah \& Uehlinger, 2001; Füreder et al., 2003). Besides these biotic variables, we identified sediment load and electrical conductivity to be related to chironomid assemblage patterns. Conductivity might not be a primal stressor for invertebrates but differs significantly between rhitral and kryal stream sites (Hieber et al., 2003) and is significantly related to invertebrate patterns in recent studies (Mori et al., 2011; Brown et al., 2015). Although we did not quantify disturbance, we derived sediment load as a proxy for hydraulic stress, which integrates discharge and concentration of suspended solids. Both variables, conductivity and sediment load, integrate several hydrological and geochemical processes, allowing conclusions about glacial activity, streambed stability (Milner et al., 2001), or even disturbance. We are aware that other influences, which were not assessed in this study, might differ between years in most sites and consequently also trigger species occurrence and survival in these habitats. However, although the explanatory power is a bit lower compared to similar habitats with $52 \%$ (Lods-Crozet et al., 2001b), the identified environmental factors were significantly related to the structure of chironomid communities and explained most of their variation within our studied streams, thereby characterising most of the niche space of chironomidae in alpine and sub-alpine streams. This dependent relationship of species occurrence and prevailing environmental situation confirms the indicative potential of the chironomids as a tool for stream ecologists in alpine/subalpine zones. Furthermore, most of these factors will be altered due to climate change and anthropogenic impacts (Brown et al., 2015) and thus will be seen in chironomid assemblage structure. Our results extend the general understanding of chironomid autecology complementing the conceptual model of Milner et al. (2001) and expanding the findings of Lods-Crozet et al. (2001a) and Lencioni et al. (2012) with a high taxonomic resolution. For example, Diamesinae species and typically upstream Orthocladiinae were well separated from the other chironomid taxa by low temperatures, high conductivity and inorganic sediment load. In contrast, warmer habitats in the sub-alpine zone with high organic matter deposition as well as higher density of primary producers favoured the establishment of assemblages dominated by Orthocladiinae species like T. bavarica, T. calvescens, E. fittkaui/ minor-gr. and E. fuldensis. This pattern of dominant species was not found in studies focussing on streams in the alpine region only (Lods-Crozet et al., 2001a, 2012). The difference is explainable by the coverage of a shorter gradient of different environmental conditions, when compared to this work. 
Definition of stream-type specific assemblages in the alpine zone

In contrast to previous studies dealing with alpine stream environments (e.g. Füreder et al., 2001; LodsCrozet et al., 2001a; Lencioni \& Rossaro, 2005), our data from Central European Alps clearly document the dominance of chironomids in alpine and sub-alpine streams and identify the most dominant species for each type. Chironomid density was significantly higher in non-glacial sites than in glacial streams, a finding supported by previous studies (e.g. Füreder et al., 2001; Lencioni \& Rossaro, 2005). Such patterns show that heterogeneous, but stable habitats favour high population densities, while dynamic environments are poorly populated (Staudacher \& Füreder, 2007; Lencioni et al., 2011). Within these reaches, chironomid community structure changed marginally within the summer months, which is in disagreement with the recent findings of Brown et al. (2015). However, this difference might arise from the lower altitude and greater distance from the glacial margin of our sites, where conditions might be more stable.

Differences in key environmental variables like water temperature, sediment load, conductivity, FPOM and periphyton, chlorophyll $a$ content led to the formation of significantly distinct and stream-type specific chironomid assemblages in the investigated watersheds. Cluster analyses revealed that chironomid communities were in general assembled and dominated by the same species in high elevation and extreme habitats of similar stream types in two different valleys separated by steep mountains (this has not been previously demonstrated). This distinction of stream-type specific assemblages with 'indicator taxa' was very clear for upstream reaches above the treeline, whereas no strict stream-type specificity could be observed in the rhithral reaches below the treeline, and this was probably caused by the differences in the slope, vegetation coverage and streambed structure between both valleys. This pattern, underlining the importance of the heterogeneous nature of the highest-altitude headwaters for regional-scale biodiversity, was genetically shown by Finn et al. (2013) and now supported by structural ecological methods.

Our study identifies constantly dominant indicator taxa such as D. steinboecki and D. latitarsis-gr. I for glacial, and P. parva, D. cinerella/zernyi-gr., and $O$. frigidus for non-glacial headwater streams. This set of invertebrates dominating associated stream types will facilitate the design of studies focusing on functional alterations in alpine stream habitats such as development, feeding preferences or production. In addition to reports about dominating species along a glacier-fed stream (Lods-Crozet et al., 2001a), this is the first study providing indicator taxa constantly dominating in glacial or non-glacial alpine stream types within the most abundant and taxonomically most difficult freshwater invertebrate family.

Niche differentiation in a multi-species community

The observed patterns of chironomid occurrence confirmed a high stream type specificity of some taxa, which implies narrow preferences along certain smallscale environmental gradients. One of the longest unresolved problems in ecology, the critical role that niche differences have in stabilising species diversity and community dynamics has been addressed in several studies (Levine \& HilleRisLambers, 2009; Vergnon et al., 2009). However, instead of comparing niche-based processes with neutral models (Vergnon et al., 2009), we provided modelled requirement-based species preferences in relation to key-environmental variables that mostly affect community structures. While other studies have used coarse indices to quantify glacial influence and selected indicator species for their changes (Khamis et al., 2014), we used reach-scale environmental variables to understand the local stressors provoking different community structures. Nevertheless, we identified similar patterns and indicator taxa.

We modelled the environmental stressors in the multidimensional environment defined by the variables that mostly affect the structure of chironomid communities. We were able to put narrower limits on environmental preferences for most of the abundant key taxa by conducting weighted averaging regression models and therefore obtaining optima and preference ranges along gradients of selected non-interacting habitat variables and abiotic environmental conditions. The combination of these modelled one-dimensional tolerances represents the main part of the species environmental niches. The models reveal a variety of preference types of the chironomid species for key environmental variables in the studied alpine 
and sub-alpine streams and identify stenoecious and euryoecious taxa with preferences for both low and high environmental extremes. Among the most frequent chironomids, we identified stenoecious taxa preferring high and low values of respective variables; thus, these taxa are as indicators highly sensitive to environmental change.

Inorganic sediment load is influenced by substrate composition, its stability, the glacial extend and its melting rate. This factor is crucial for the formation of communities in glacier-fed headwaters, and it separates cold stenothermal Diamesinae species living in clear non-glacial streams (D. cinerella/zernyi-gr. and $P$. parva) from other Diamesinae tolerating high contents of fine rock fragments and turbid waters $(D$. steinboecki, D. latitarsis-gr. I and II). Thus, tolerating high sediment loads seems to be more crucial for survival in glacier-fed streams than withstanding cold water temperatures as suggested by other studies (Lods-Crozet et al., 2001a; Milner et al., 2001; Lencioni \& Rossaro, 2005). The modelled optima may not directly reflect fundamental optima of Diamesinae species, as these species might also tolerate higher water temperatures and low sediment loads, or high concentration of suspended solids, but are competitively excluded from benign stream sites by other chironomid species as suggested by Castella et al. (2001). Still, our models illustrate the adaptation and environmental tolerance of this species group, being able to withstand harsh conditions, which we found to be their niche in alpine streams. Although we applied a different approach in contrast to other authors (Khamis et al., 2014), we congruently identified several species adapted to a high glacial influence (several Diamesa species). We are aware that the geographic scope of this study, which covered remote parts of the Eastern Alps, is relatively small compared to the geographic distribution of the chironomid species identified (e.g. D. latitarsis (Goetghebuer), O. frigidus). However, the investigation of distinct stream types at different altitudes (from alpine glacial streams to non-glacial streams with high inputs of allochthonous material) allowed us to include data from a broad suite of environmental gradients. Additionally, we modelled unimodal and multifactorial species response curves which had not previously been computed for alpine stream invertebrates by weighted averaging regression models. This technique facilitates the coverage of a wide range of possible environmental conditions where most alpine and sub-alpine chironomid species occur.

For the ordination, clustering and the modelling of optima and tolerance of communities and species, we partially included non-independent samples (e.g. different microhabitats in the same stream reach or the same stream reaches at different seasons), thus leading to an over-estimation of the statistical power of these analyses due to partial spatial and temporal autocorrelation. Nevertheless, these approaches permitted the estimation of the seasonal stability of the communities and facilitated the interpretation of the sample scale (e.g. FPOM, CPOM) and reach scale environmental preferences (e.g. temperature, sediment load) of the species within the studied streams.

The confirmation of the dependency of chironomid species on key environmental factors, the classification of species according to their preferences, as well as the demonstration of environmental niches (e.g., $D$. cinerella/zernyi-gr. in clear, 'high' conductive waters with low and stable temperatures or D. steinboecki in streams with high inorganic sediment loads, low primary production and FPOM content), enabled the creation of a new set of autecological information including environmental preferences and tolerance ranges of chironomid key species in alpine and subalpine stream ecosystems in the Central Alps. The most appropriate monitoring taxa can now be selected according to their width of environmental tolerance, relative abundances and frequencies.

In contrast to studies that related invertebrate structures and indicator taxa to altering environmental conditions in glacier-fed streams (Lods-Crozet et al., 2001a; Milner et al., 2001; Jacobsen et al., 2012; Khamis et al., 2014) and single non-glacial tributaries (Füreder et al., 2001), however, we described the typical communities and indicative chironomid species, along with identifying key environmental factors influencing these structures, and confined suitable environmental conditions of the most abundant species for both glacial and non-glacial streams. Nevertheless, we are aware of the presence of a temporal and spatial overlap of these preferences and niche mechanisms based on the organism's functional role. The functions performed by each chironomid taxa such as the different feeding strategies, specific food sources and processing in-stream products (Wallace \& Webster, 1996; Füreder et al., 2003; Clitherow et al., 2013) may also lead to niche differentiation. 
Glacier melt and anthropogenic influence have become increasingly apparent in alpine stream ecosystems (Füreder, 2012; Jacobsen et al., 2012), so too has the demand for reliable predictions of future alterations in such ecosystems. The findings of this study demonstrated the potential to deduce in-stream environmental conditions by the observation of community structure. The combination of identifying streamtype-specific communities and verifying their fidelity in occurrence in different watersheds, allowed modelled response curves for adequate indicator and monitoring species in alpine and sub-alpine streams. For that purpose, the definition of preferences for local environmental conditions (certain combination of species-specific optima and tolerance for different local environmental variables) was applied for alpine and sub-alpine invertebrates to identify not only the best-fitting indicators but also the species vulnerable to environmental change based on their ecological limitations (Beck, 2013). Autecological data of stream organisms together with hydrological prospects (Milner et al., 2009; Naz et al., 2014; Gan et al., 2015) is essential for forecasting future ecological situations and trends in alpine streams. Furthermore, the oftendebated low accuracy of models projecting ecosystem change (Pearson \& Dawson, 2003; Midgley et al., 2007; Brook et al., 2009) can definitely be improved using a robust taxonomy and a comprehensive and detailed set of physical and chemical data as presented in this study.

Acknowledgements The research was carried out within the project "Monitoring Alpine Rivers", funded by the Nationalparkrat Hohe Tauern, the "Austrian Federal Ministry of Agriculture and Forestry, Environment and Water Management', the federal states Salzburg, Carinthia, Tyrol and the European Union (European Agricultural Fund for Rural Development). We are very grateful to Stefanie Aumayr, Alexandra Mätzler, Nikolaus Medgyesy, Sabrina Schönenberger and Ursula Windner for their help during the fieldwork and thanks to Josef Franzoi, Gry Larsen and Salvador Morales-Gomez for the chemical analyses. The authors acknowledge Paul Fraiz for help with language editing.

Open Access This article is distributed under the terms of the Creative Commons Attribution 4.0 International License (http:// creativecommons.org/licenses/by/4.0/), which permits unrestricted use, distribution, and reproduction in any medium, provided you give appropriate credit to the original author(s) and the source, provide a link to the Creative Commons license, and indicate if changes were made.

\section{References}

Anderson, M. J., 2005. PERMANOVA: a FORTRAN computer program for permutational multivariate analysis of variance. University of Auckland, Auckland.

Beck, J., 2013. Predicting climate change effects on agriculture from ecological niche modeling: who profits, who loses? Climatic Change 116: 177-189.

Begon, M., J. L. Harper \& C. R. Townsend, 1996. Ecology. Individuals, Populations, and Communities, 3rd ed. Blackwell Science, Oxford.

Beniston, M., 2005. Mountain climates and climatic change: an overview of processes focusing on the European Alps. Pure and Applied Geophysics 162: 1587-1606.

Blanchet, F. G., P. Legendre \& D. Borcard, 2008. Forward selection of explanatory variables. Ecology 89: 2623-2632.

Blonder, B., C. Lamanna, C. Violle \& B. J. Enquist, 2014. The $n$ dimensional hypervolume. Global Ecology and Biogeography 23: 595-609.

Bouchard, R., M. Carrillo, S. Kells \& L. Ferrington Jr., 2006. Freeze tolerance in larvae of the winter-active Diamesa mendotae Muttkowski (Diptera: Chironomidae): a contrast to adult strategy for survival at low temperatures. Hydrobiologia 568: 403-416.

Braun, L. N., M. Weber \& M. Schulz, 2000. Consequences of climate change for runoff from Alpine regions. Annals of Glaciology 31: 19-25.

Brittain, J. E. \& A. M. Milner, 2001. Ecology of glacier-fed rivers: current status and concepts. Freshwater Biology 46: 1571-1578.

Brook, B. W., H. R. Akcakaya, D. A. Keith, G. M. Mace, R. G. Pearson \& M. B. Araujo, 2009. Integrating bioclimate with population models to improve forecasts of species extinctions under climate change. Biology Letters 5: 723-725.

Brown, E. L., A. M. Milner \& D. M. Hannah, 2006a. Stability and persistence of alpine stream macroinvertebrate communities and the role of physicochemical habitat variables. Hydrobiologia 560: 159-173.

Brown, E. L., D. M. Hannah \& A. M. Milner, 2006b. Hydroclimatological influences on water column and streambed thermal dynamics in an alpine river system. Journal of Hydrology 325: 1-20.

Brown, E. L., A. M. Milner \& D. M. Hannah, 2007. Vulnerability of alpine stream biodiversity to shrinking glaciers and snowpacks. Global Change Biology 13: 958-966.

Brown, L. E., N. E. Dickson, J. L. Carrivick \& L. Füreder, 2015. Alpine river ecosystem response to glacial and anthropogenic flow pulses. Freshwater Science 34: 1201-1215.

Butler, S. J., R. P. Freckleton, A. R. Renwick \& K. Norris, 2012. An objective, niche-based approach to indicator species selection. Methods in Ecology and Evolution 3: 317-326.

Castella, E., H. Adalsteinsson, J. E. Brittain, G. M. Gislason, A. Lehmann, V. Lencioni, B. Lods-Crozet, B. Maiolini, A. M. Milner, J. S. Olafsson, S. J. Saltveit \& D. L. Snook, 2001. Macrobenthic invertebrate richness and composition along a latitudinal gradient of European glacier-fed streams. Freshwater Biology 46: 1811-1831. 
Clitherow, L. R., J. L. Carrivick, L. E. Brown \& L. F. Bersier, 2013. Food web structure in a harsh glacier-fed river. PLoS One 8: e60899.

Danks, H. V., 1971. Overwintering of some north temperate and arctic Chironomidae. II. Chironomid biology. Canadian Entomologist 103: 1875-1910.

Danks, H. V. \& D. R. Oliver, 1972. Seasonal emergence of some high arctic Chironomidae (Diptera). Canadian Entomologist 104: 661-686.

Dufrêne, M. \& P. Legendre, 1997. Species assemblages and indicator species: the need for a flexible asymmetrical approach. Ecological Monographs 67: 345-366.

Ferrarese, U. \& B. Rossaro, 1981. Chironomidi 1. (Diptera: Chironomidae: Generalitá, Diamesinae, Prodiamesinae). Museo Civico di Storia Naturale di Verona, Verona.

Finn, S. D., K. Khamis \& A. M. Milner, 2013. Loss of small glaciers will diminish beta diversity in Pyrenean streams at two levels of biological organization. Global Ecology and Biogeography 22: 40-51.

Fjellheim, A., A. Boggero, A. M. Nocentini, M. Rieradevall, G. G. Raddum \& Ø. Schnell, 2000. Distribution of benthic invertebrates distribution of benthic invertebrates in relation to environmental factors. A study of European remote alpine lake ecosystems. Verhandlungen der Internationale Vereinigung für Theoretische und Angewandte Limnologie 27: 484-488.

Füreder, L., 1999. High alpine streams: cold habitats for insect larvae. In Margesin, R. \& F. Schinner (eds), Cold-adapted organisms. Springer, Berlin: 181-196.

Füreder, L. \& K. Amprosi, 2001. Gewässerinventar für den Nationalpark Hohe Tauern (Kärnten, Salzburg, Tirol, Österreich). Wissenschaftliche Mitteilungen aus dem Nationalpark Hohe Tauern 6: 213-240.

Füreder, L., C. Schütz, M. Wallinger \& R. Burger, 2001. Physico-chemistry and aquatic insects of a glacier-fed and a spring-fed alpine stream. Freshwater Biology 46: 1673-1690.

Füreder, L., C. Vacha, K. Amprosi, S. Bühler, C. M. E. Hansen \& C. Moritz, 2002. Reference conditions of alpine streams: physical habitat and ecology. Water, Air \& Soil Pollution: Focus 2: 275-294.

Füreder, L., C. Welter \& J. K. Jackson, 2003. Dietary and stable isotope $\left(\delta^{13} \mathrm{C}, \delta^{15} \mathrm{~N}\right)$ analyses in alpine stream insects. International Review of Hydrobiology 88: 314-331.

Füreder, L., 2007. Life at the edge: habitat condition and bottom fauna of alpine running waters. International Review of Hydrobiology 92: 491-513.

Füreder, L., 2012. Freshwater ecology: melting biodiversity. Nature Climate change 2: 318-319.

Gan, R., Y. Luo, Q. Zuo \& L. Sun, 2015. Effects of projected climate change on the glacier and runoff generation in the Naryn River Basin, Central Asia. Journal of Hydrology 523: 240-251.

Giersch, J. J., S. Jordan, G. Luikart, L. A. Jones, F. R. Hauer \& C. C. Muhlfeld, 2015. Climate-induced range contraction of a rare alpine aquatic invertebrate. Freshwater Science 34: 53-65.

Grinnell, J., 1917. The niche-relationships of the California Thrasher. Auk 34: 427-433.
Hammer, Ø., D. A. Harper \& P. D. Ryan, 2001. PAST: paleontological statistics software package for education and data analysis. Palaeontologia Electronica 4: 1-9.

Heiri, O., A. F. Lotter \& G. Lemcke, 2001. Loss on ignition as a method for estimating organic and carbonate content in sediments: reproducibility and comparability of results. Journal of Paleolimnology 25: 101-110.

Hieber, M., C. T. Robinson \& U. Uehlinger, 2003. Seasonal and diel patterns of inbertebrate drift in different alpine stream types. Freshwater Biology 48: 1078-1092.

Hirzel, A. H. \& G. Le Lay, 2008. Habitat suitability modeling and niche theory. Journal of Applied Ecology 45: 1372-1381.

Horn, W., W. Kohl \& P. E. Schmidt, 1993. Wasser und Abwasser. A key to the larval chironomidae and their instars from Austrian Danube region streams and rivers with particular reference to a numerical taxonomic approach. Supplementary Volume 3, 514 pp., Publisher: Federal Institut for Water Quality Wien, 1993. ISBN 3-900672-92-X. ÖS 562.-. Internationale Revue der gesamten Hydrobiologie und Hydrographie 79: 422.

Hutchinson, G. E., 1957. Concluding remarks. Cold Spring Harbor Symposia on Quantitative Biology 22: 415-427.

Jansson, P., R. Hock \& T. Schneider, 2003. The concept of glacier storage: a review. Journal of Hydrology 282: 116-129.

Jacobsen, D., A. M. Milner, L. E. Brown \& O. Dangles, 2012. Biodiversity under threat in glacier-fed river systems. Nature Climate Change 2: 361-364.

Juggins, S., 2007. User Guide C2: software for Ecological and Palaeoecological Data Analysis and Visualization. University of Newcastle, Newcastle.

Khamis, K., D. M. Hannah, L. E. Brown, R. Tiberti \& A. M. Milner, 2014. The use of invertebrates as indicators of environmental change in alpine rivers and lakes. Science of the Total Environment 493: 1242-1254.

Kindt, R. \& R. Coe, 2005. Tree diversity analysis. A manual and software for common statistical methods for ecological and biodiversity studies. Nairobi: World Agroforestry Centre (ICRAF).

Knowles, N., M. D. Dettinger \& D. R. Cayan, 2006. Trends in snowfall versus rainfall in the Western United States. Journal of Climate 19: 4545-4559.

Legendre, P. \& L. Legendre, 1998. Numerical Ecology, 2nd ed. Elsevier, Amsterdam.

Lencioni, V., L. Marziali \& B. Rossaro, 2011. Diversity and distribution of chironomids (Diptera, Chironomidae) in pristine alpine and pre-alpine springs (Northern Italy). Journal of Limnology 70: 106-121.

Lencioni, V., L. Marziali \& B. Rossaro, 2012. Chironomids as bioindicators of environmental quality in mountain springs. Freshwater Science 31: 525-541.

Lencioni, V. \& B. Rossaro, 2005. Microdistribution of chironomids (Diptera: Chironomidae) in alpine streams: an autoecological perspective. Hydrobiologia 533: 61-76.

Lepš, J. \& P. Šmilauer, 2003. Multivariate Analysis of Ecological Data Using CANOCO. Cambridge University Press, Cambridge.

Levine, M. J. \& J. HilleRisLambers, 2009. The importance of niches for the maintenance of species diversity. Nature Letters 461: 254-258. 
Li, F., N. Chung, M. Bae, Y. Kwon \& Y. Park, 2012. Relationships between stream macroinvertebrates and environmental variables at multiple spatial scales. Freshwater Biology 57: 2107-2124.

Lods-Crozet, B., V. Lencioni, J. S. Olafsson, D. L. Snook, G. Velle, J. E. Brittain, et al., 2001a. Chironomid (Diptera: Chironomidae) communities in six European glacier-fed streams. Freshwater Biology 46: 1791-1809.

Lods-Crozet, B., E. Castella, D. Cambin, C. Ilg, S. Knispel \& H. Mayor-Simeant, 2001b. Macroinvertebrate community structure in relation to environmental variables in a swiss glacial stream. Freshwater Biology 46: 1641-1661.

Lods-Crozet B., B. Oertli \& C. T. Robinson, 2012. Long-term patterns of chironomid assemblages in a high elevated stream/lake network (Switzerland) - Implications to global change. Proceedings of the 18th International Symposium on Chironomidae - Fauna norvegica 31: 71-85.

Lorenzen, C. T., 1967. Chlorophyll and pheo-pigments: spectrophotometric equations. Limnology and Oceanography 12: 343-346.

McCune, B., J. B. Grace \& D. L. Urban, 2002. Analysis of Ecological Communities. MjM Software Design, Gleneden Beach.

McCune, B. \& J. Mefford, 2006. PC-Ord. Multivariate Analysis of Ecological Data, Version 5.07. MjM Software Design. Glenedon Beach, Oregon.

McGregor, G., G. E. Petts, A. M. Gurnell \& A. M. Milner, 1995. Sensitivity of alpine stream ecosystems to climate change and human impacts. Aquatic Conservation: Marine and Freshwater Ecosystems 5: 233-247.

Midgley, G. F., S. L. Chown \& B. S. Kgope, 2007. Monitoring effects of anthopogenic climate change on ecosystems: a role for systematic ecological observation? South African Journal of Science 103: 282-286.

Milner, A. M. \& G. E. Petts, 1994. Glacial Rivers: physical habitat and ecology. Freshwater Biology 32: 295-307.

Milner, A. M., J. E. Brittain, E. Castella \& G. E. Petts, 2001. Trends of macroinvertebrate community structure in glacier-fed rivers in relation to environmental conditions: a synthesis. Freshwater Biololgy 46: 1833-1847.

Milner, A. M., L. E. Brown \& D. M. Hannah, 2009. Hydroecological response of river systems to shrinking glaciers. Hydrological Process 23: 62-77.

Mori, N., T. Simčič, S. Lukančič \& A. Brancelj, 2011. The effect of in-stream gravel extraction in a pre-alpine gravel-bed river on hyporheic invertebrate community. Hydrobiologia 667: $15-30$.

Muhlfeld, C. C., J. J. Giersch, F. R. Hauer, G. T. Pederson, G. Luikart, D. P. Petersen, C. C. Downs \& D. B. Fagre, 2011.
Climate change links fate of glaciers and an endemic alpine invertebrate - A letter. Climatic Change 106: 337-345.

Naz, B. S., C. D. Frans, G. K. C. Clarke, P. Burns \& D. P. Lettenmaier, 2014. Modeling the effect of glacier recession on streamflow response using a coupled glacio-hydrological model. Hydrological Earth System Science 18: 787-802.

Pearson, R. G. \& T. P. Dawson, 2003. Predicting the impacts of climate change on the distribution of species: are bioclimate envelope models useful? Global Ecology and Biogeography 12 : 361-371.

Rossaro, B., 1982. Chironomidi, 2. (Diptera: Chironomidae: Orthocladiinae). Museo Civico di Storia Naturale di Verona, Verona.

Šmilauer, P. \& C. J. F. ter Braak, 2012. CANOCO Reference Manual and User's Guide: software for Ordination (version 5.0). Microcomputer Power, Ithaca.

Soberón, J., 2007. Grinnellian and Eltonian niches and geographic distributions of species. Ecology Letters 10: 1115-1123.

Staudacher, K. \& L. Füreder, 2007. Habitat complexity and invertebrates in selected alpine springs (Schütt, Carinthia, Austria). International Review of Hydrobiology 92: 465-479.

ter Braak, C. J. F. \& S. Juggins, 1993. Weighted averaging partial least squares regression (WA-PLS): an improved method for reconstructing environmental variables from species assemblages. Hydrobiologia 269-270: 485-502.

ter Braak, C. J. F. \& P. Šmilauer, 1998. CANOCO reference manual and User's Guide to Canoco for Windows: Software for Canonical Community Ordination (version 4). Microcomputer Power, Ithaca.

Tockner, K., F. Malard, P. Burgherr, C. T. Robinson, U. Uehlinger, R. Zah \& J. V. Ward, 1997. Physico-chemical characterization of channel types in a glacial floodplain ecosystem (Val Roseg, Switzerland). Archiv für Hydrobiologie 140: 433-463.

Vergnon, R., N. K. Dulvy \& R. P. Freckleton, 2009. Niches versus neutrality: uncovering the drivers of diversity in a species-rich community. Ecology Letters 12: 1079-1090.

Ward, J. V., 1994. Ecology of alpine streams. Freshwater Biology 32: 277-294.

Wharton, D. A., 2002. Life at the Limits. Organisms in Extreme Environments. Cambridge University Press, Cambridge.

Zah, R. \& U. Uehlinger, 2001. Particulate organic matter inputs to a glacial stream ecosystem in the Swiss Alps. Freshwater Biology 46: 1597-1608.

Zemp, M., W. Haeberli, M. Hoelzle \& F. Paul, 2006. Alpine glaciers to disappear within decades? Geophysical Research Letters 33: L13504. 